\title{
Insecticide-treated Netting Materials for Malaria Vector Control: A Simplified Study Protocol for Assessing Residual Bio-efficacy, Community Perceptions, Practices and Durability of the Field-distributed Nets
}

\author{
Vas Dev* \\ Senior Scientist (Retired), National Institute of Malaria Research, New Delhi, India
}

Article Info

\section{Article Notes}

Received: August 27, 2018

Accepted: September 26, 2018

\section{${ }^{*}$ Correspondence:}

Dr. Vas Dev, House No. 656, Sector 9, Urban Estate, Ambala City - 134003, Haryana, India; Telehone No: 919435345154: Email: mrcassam@hotmail.com

${ }^{0} 2018$ Dev V. This article is distributed under the terms of the Creative Commons Attribution 4.0 International License.

\section{Keywords:}

Malaria

Anopheles

Long-lasting insecticidal nets

Monitoring and evaluation

Residual bio-efficacy

Vector control

\begin{abstract}
Long-lasting insecticidal nets are being promoted as evidence-based intervention for malaria vector control globally. In keeping with increased procurement and supplies, it was mandated to monitor and evaluate fielddistributed nets for residual bio-efficacy and physical integrity. Towards this objective, a simplified study protocol is proposed which can be conveniently employed to assess the current bio-efficacy to help programme officials making informed decisions for additional logistics enabling net replacement in due time.
\end{abstract}

\section{Introduction}

In the past decade, there has been substantial decline in reported cases and attributable deaths in the malaria-endemic countries ${ }^{1}$. Much can be attributed to rollout of two major interventions: (i) artemisinin-based combination therapies (ACTs) for treatment of malaria, (ii) long-lasting insecticidal nets (LLINs) and indoor residual spraying for vector control. Based on these core-interventions, India registered significant decline in cases and malaria-attributable deaths over the past few years and has embarked upon malaria elimination by universalization of evidence-based interventions, monitoring and evaluation, and strengthening healthcare services prioritizing high-risk areas ${ }^{2.3}$. In India, additional provisions are being made both at subnational and national level for mass-scale distribution of LLINs each passing year. To help formulate policy for net procurement, supplies and replacement, a study was undertaken in high-risk districts of Assam, northeast India to ascertain the current residual bio-efficacy of the previously distributed LLINs, net durability, and community practices for benefit of programme managers ${ }^{4}$. An outcome of this study project resulted in development of protocol given below which can be practiced in different malaria endemic zones enabling sustained allocation of resources for continued attack on disease vector populations disrupting transmission.

\section{Methods and Data Collection}

This exercise should preferably be a cross-sectional study undertaken during months of high transmission and peak mosquito vector density at multiple locations in beneficiary population groups recipient of LLINs in coordination with local district/state health authorities. 


\section{Topography, climate and study populations}

At the very outset,identify the high-risk pockets based on parasite incidence for the preceding three years in selected districts of the state and ensure logistic support for smooth conduct of investigations. Collect data on population census of the chosen sites, record of net distribution for month/ year, type of LLIN (brand name, polyethylene or polyester fibre, denier strength, net dimensions, concentration of pyrethroid $\mathrm{mg} / \mathrm{m}^{2}$, manufacturing date etc.), and number of nets provided per household for each location. Briefly describe the geo-epidemiological conditions of study location giving climatic determinants, population census, housing pattern, and access to available healthcare services and control interventions in practice.

\section{Mosquito vector abundance and insecticide susceptibility status}

To begin with, systematic entomological surveys should be done in selected index villages reporting high case incidences to ascertain anopheline fauna and relative prevalence of known disease vector species, and present susceptibility status to residual insecticides. Mosquito adult collections should be made by active searches early morning hours (06:00-08:00 h) as well as evening hours (18:00-20:00 h) in different habitats (resting populations indoor human dwellings and outdoor shelters) in each study location by hand catch method aided by mosquito suction tube and battery torch light. These data should be collated for mosquito density for each prevalent species in respective habitat (Table 1 ).

These mosquito collections may be supplemented by CDC miniature light traps both indoors and outdoors as well as rearing larval collections till adult emergence. The field-collected vector mosquitoes should be subjected to insecticide susceptibility tests using WHO standard test kit procedures against diagnostic concentration of the residual insecticide in use for indoor spraying (if any) as well as pyrethroid that has been employed in distributed LLINs 5 . Additional data may be generated for sporozoite infectivity and parity restricted to suspected/proven mosquito vector species. These data are crucial to determine impact on mosquito vector populations in relation to new intervention.

\section{Monitoring residual bio-efficacy}

Residual bio-efficacy should be assessed against each candidate mosquito vector species for which WHO standard cone-bioassay test procedures should be employed to determine persistence and bio-availability of insecticide on netting fibre ${ }^{6}$. For this purpose, three LLINs (in use by the households) should be randomly drawn keeping one untreated net as control for comparative purposes. Field collected mosquito adult females of candidate vector species (s) should be exposed in WHO test bio-assay cones against net in hanging position for 03 (three) minutes for minimum of five replicates in batches of 10 mosquitoes for each test ( $10 \times 5=50$ adults). Number of mosquitoes knock-down after exposure period and dead post $24 \mathrm{~h}$ recovery period should be recorded (Table 2).

These data can be supplemented by ring-net bioassay test to substantiate residual bio-efficacies for which 11 mosquito adult females should be exposed in ring-net against net fibre and time required for knock-down of $1^{\text {st }}$, $6^{\text {th }}$ and $11^{\text {th }}$ mosquito should be recorded for maximum

Table 1. Relative abundance of anopheline mosquito species in study blocks /districts ${ }^{\mathrm{a}}$

\begin{tabular}{|l|l|l|l|l|l|}
\hline \multirow{2}{*}{$\begin{array}{l}\text { Anopheles }(A n .) \\
\text { mosquito species }\end{array}$} & $\begin{array}{l}\text { So. of mosquitoes } \\
\text { collected in human } \\
\text { dwellings indoors } \\
\text { (person hour density) }\end{array}$ & $\begin{array}{l}\text { No. of mosqui- } \\
\text { toes collected in } \\
\text { outdoor shelters } \\
\text { (person hour } \\
\text { density) }\end{array}$ & $\begin{array}{l}\text { No. of mosquitoes } \\
\text { collected in human } \\
\text { dwellings indoors } \\
\text { (person hour } \\
\text { density) }\end{array}$ & $\begin{array}{l}\text { No. of mosquitoes } \\
\text { collected in outdoor } \\
\text { shelters (person } \\
\text { hour density) }\end{array}$ & $\begin{array}{l}\text { No. of mosquitoes } \\
\text { collected in human } \\
\text { dwellings indoors } \\
\text { (person hour }\end{array}$ \\
density)
\end{tabular}

a Study period

${ }^{b}$ Number of mosquitoes collected per person-hour

Table 2. Residual bio-efficacies of field-distributed long-lasting insecticidal nets in use by householders expressed in terms of percent knockdown of mosquito species post 03 minutes exposure and mortality post 24 hours recovery period by contact cone-bioassay test method

\begin{tabular}{|c|c|c|c|c|c|c|c|}
\hline \multirow[t]{3}{*}{ Type of LLIN } & \multirow{3}{*}{$\begin{array}{c}\text { Manufacturing date } \\
\text { (month of distribution) }\end{array}$} & \multicolumn{6}{|c|}{ Study location (Block/District) } \\
\hline & & \multicolumn{2}{|c|}{ Location \# 1} & \multicolumn{2}{|c|}{ Location \# 2} & \multicolumn{2}{|c|}{ Location \# 3} \\
\hline & & $\begin{array}{l}\text { No. \& (\%) } \\
\text { mosquitoes } \\
\text { knockdown post } \\
3 \text { min exposure/ } \\
\text { total exposed }\end{array}$ & $\begin{array}{l}\text { No. \& (\%) } \\
\text { mosquitoes } \\
\text { dead post } 24 \mathrm{~h} \\
\text { exposure/ total } \\
\text { exposedc }\end{array}$ & $\begin{array}{l}\text { No. \& (\%) } \\
\text { mosquitoes } \\
\text { knockdown post } \\
3 \text { min exposure/ } \\
\text { total exposed }\end{array}$ & $\begin{array}{l}\text { No. \& (\%) } \\
\text { mosquitoes } \\
\text { dead post } 24 \mathrm{~h} \\
\text { exposure/ total } \\
\text { exposed }\end{array}$ & $\begin{array}{l}\text { No. \& (\%) } \\
\text { mosquitoes } \\
\text { knockdown post } \\
3 \text { min exposure/ } \\
\text { total exposed }\end{array}$ & $\begin{array}{l}\text { No. \& (\%) } \\
\text { mosquitoes } \\
\text { dead post } 24 \mathrm{~h} \\
\text { exposure/ } \\
\text { total exposed }\end{array}$ \\
\hline
\end{tabular}

\footnotetext{
a Study period
}

${ }^{\mathrm{b}}$ data based on exposure of 10 mosquitoes per cone-bioassay

${ }^{\mathrm{c}}$ mosquito mortality $<80 \%$ denotes depletion of residual insecticide on fibre than optimum 
Table 3. Ring-net bioassay test results of the field-distributed long-lasting insecticidal nets in use by the householders ${ }^{\mathrm{a}}$

\begin{tabular}{|c|c|c|c|c|c|c|c|c|c|c|}
\hline \multirow{4}{*}{ Type of LLIN } & \multirow{4}{*}{$\begin{array}{c}\text { Manufacturing date } \\
\text { (month of distribution) }\end{array}$} & \multicolumn{9}{|c|}{ Study location (Block/District) } \\
\hline & & \multicolumn{3}{|c|}{ Study location \# 1} & \multicolumn{3}{|c|}{ Study location \# 2} & \multicolumn{3}{|c|}{ Study location \# 3} \\
\hline & & \multicolumn{3}{|c|}{$\begin{array}{l}\text { Mosquito knock-down time } \\
\text { in minutes } \quad(\text { mean } \pm \text { SD })^{\text {b }}\end{array}$} & \multicolumn{3}{|c|}{$\begin{array}{l}\text { Mosquito knock-down time } \\
\text { in minutes (mean } \pm \text { SD) }\end{array}$} & \multicolumn{3}{|c|}{$\begin{array}{l}\text { Mosquito knock-down time in } \\
\text { minutes (mean } \pm \text { SD) }\end{array}$} \\
\hline & & $1^{\text {st }}$ & $6^{\text {thc }}$ & $11^{\text {th }}$ & $1^{\text {st }}$ & $6^{\text {th }}$ & $11^{\text {th }}$ & $1^{\text {st }}$ & $6^{\text {th }}$ & $11^{\text {th }}$ \\
\hline
\end{tabular}

a Study period

${ }^{b}$ Data based on exposure of 11 mosquitoes per ring-net bioassay

'Median knockdown time for $6^{\text {th }}$ mosquito of $>10$ minutes denotes significant depletion of residual insecticide on netting fibre

Table 4. Comparative assessment of physical integrity of long-lasting insecticidal nets (LLINs) in use by the communities ${ }^{\mathrm{a}}$

\begin{tabular}{|c|c|c|c|c|}
\hline \multirow[b]{2}{*}{ S. No } & \multirow[b]{2}{*}{ Question } & \multicolumn{2}{|c|}{ Physical condition of } & \multirow[b]{2}{*}{ Any } \\
\hline & & $\begin{array}{c}\text { Type of LLIN } \\
\mathbf{N}^{\mathrm{b}}=\end{array}$ & $\begin{array}{c}\text { Type of LLIN } \\
\mathbf{N}=\end{array}$ & \\
\hline 1. & No. of torn nets having holes (\% of nets inspected) & & & \\
\hline \multirow{4}{*}{2.} & Total number of holes (Number of holes/ No. of torn net) & & & \\
\hline & Small $(0.5-<2 \mathrm{~cm}$ diameter $)$ & & & \\
\hline & Medium (2-10 cm diameter) & & & \\
\hline & Large ( $>10 \mathrm{~cm}$ diameter) & & & \\
\hline \multirow{4}{*}{3.} & Total number of holes in position (Number of holes/ No. of torn net) & & & \\
\hline & Lower half of net & & & \\
\hline & Upper half of net & & & \\
\hline & Roof & & & \\
\hline \multirow{5}{*}{4.} & Physical aspect of net (Percentage of nets inspected) & & & \\
\hline & Clean & & & \\
\hline & A bit dirty & & & \\
\hline & Dirty & & & \\
\hline & Very dirty & & & \\
\hline
\end{tabular}

a Study period

${ }^{\mathrm{b}}$ Number of nets inspected

exposure of $1 \mathrm{~h}^{4}$. Time taken for knock-down of $6^{\text {th }}$ mosquito is regarded as the median knock-down time (Table 3).

\section{Community perceptions, practices and net durability}

Public perceptions should be ascertained by structured pre-tested (intuitionally approved) study protocol by verbal autopsy subject to informed consent of the adult householder for perceived benefits and adverse events (if any), net usage pattern by family members (all or only mother/children sleeping under nets throughput year/ seasonal), methods and frequency of net washing (monthly, quarterly, six-monthly by soap water or any other method), and net ownership in position/attrition rate (number still in possession of those initially distributed). For crosssectional survey, $\sim 25 \%$ of the target population should be visited and nets inspected physically for being torn, number of holes and stitches, existing condition of net etc. The holes present should be quantified and categorized by size for being small $(0.5-<2 \mathrm{~cm})$, medium $(2-10 \mathrm{~cm})$, and large $(>10 \mathrm{~cm})$, and position in lower half, upper half or roof top (Table 4). For estimation of net durability, data on proportionate hole index ( $\mathrm{pHI}$ ), available residual insecticide on netting fibre and feeding inhibition would be of added value to determine net serviceable life ${ }^{7}$.

\section{Discussion}

Vector control is an integral component of malaria control and elimination strategy for which entomological surveillance, monitoring insecticide resistance and vector behaviour are all essential for timely response to contain vector populations. LLINs are proven key-intervention for vector control and recommended worldwide for 'universal coverage'. The community acceptance of LLINs and responses have been overwhelming generating additional demands owing to perceived benefits for decreased mosquito nuisance and protection from malaria. However, the coverage of population at risk remains inadequate for lack of resources particularly in resource-poor settings. As per WHOPES criteria, the net serviceable life for maintaining optimum residual bio-efficacy (mosquito mortality $\geq 80 \%$ ) and integrity should be minimum of 03 (three) years of continuous use by the communities in field conditions ${ }^{6}$. However, investigations in different geo-epidemiological conditions revealed that residual bio-efficacy varied from 2 to $<3$ years at best warranting replacement thereafter ${ }^{4}$. While, it is considered important to scale up distribution of LLINs, it is just as crucial to monitor the bio-efficacy and serviceable life of previously distributed nets to ensure continuous protection by replacing those worn-out by 
fresh supply. There should be policy in practice to warrant such investigations for net procurement, community compliance and timely replacement to support national control programme averting return of malaria in malariafree territories. World Health Organization (WHO) aims to reduce malaria morbidity and mortality by $90 \%$ globally by 2030 compared to $2015^{\circ}$. Yet the progress towards elimination seems to have stalled with reported rise in cases in 2016 by 05 (five) million over the previous year raising alarm for appropriate actions to maintain declining trends to end transmission. It is strongly advocated to maintain vigil against emerging insecticide resistance and address the challenges of outdoor transmission by increased investments in newer tools for sustained control efforts ${ }^{9}$.

\section{Conclusion}

Monitoring residual bio-efficacy of LLINs should be inbuilt activity of the National Malaria Control Programme making provisions for net replacement providing uninterrupted protection in place and time.

\section{References}

1. World Health Organization (WHO). World Malaria Report 2017. Geneva.
2. Dhiman S, Singh V, Dev V. Declining transmission of malaria in India: accelerating towards elimination. In: Towards Malaria Elimination A leap forward. Manguin \& Dev (Eds.), InTech Open, London. 2018; 257-280.

3. National Framework for Malaria Elimination in India 2016-2030. Directorate of National Vector Borne Disease Control Programme (NVBDCP). Ministry of Health \& Family Welfare, Government of India, New Delhi. 2016; 43.

4. Dev V, Barman K, Khound K. A cross-sectional study assessing the residual bio-efficacy and durability of field-distributed long-lasting insecticidal nets in malaria endemic ethnic communities of Assam, Northeast India. J Infect Public Health. 2016; 9(3): 298-307.

5. World Health Organization. Test procedures for insecticide resistance monitoring in malaria vector mosquitoes. Global Malaria programme. $2^{\text {nd }}$ Edition; 48.

6. World Health Organization. Communicable Disease Control, Prevention and Eradication,WHO Pesticide Evaluation Scheme (WHOPES). Guidelines for laboratory and field testing of long-lasting insecticidal mosquito nets. WHO/CDS/WHOPES/GCDPP/2005.11.

7. World Health Organization. Guidelines for monitoring the durability of long-lasting Insecticidal mosquito nets under operational conditions. WHO/HTM/NTD/WHOPES. Geneva: World Health Organization, 2011.5.

8. World Health Organization (WHO). Global Technical Strategy for malaria 2016-2030. Global Malaria Programme. Geneva: World Health Organization. 2015; 30.

9. Roll Back Malaria Partnership. Investing for a malaria-free world. Action and Investment to defeat Malaria 2016-2030 (AIM), 2015. 